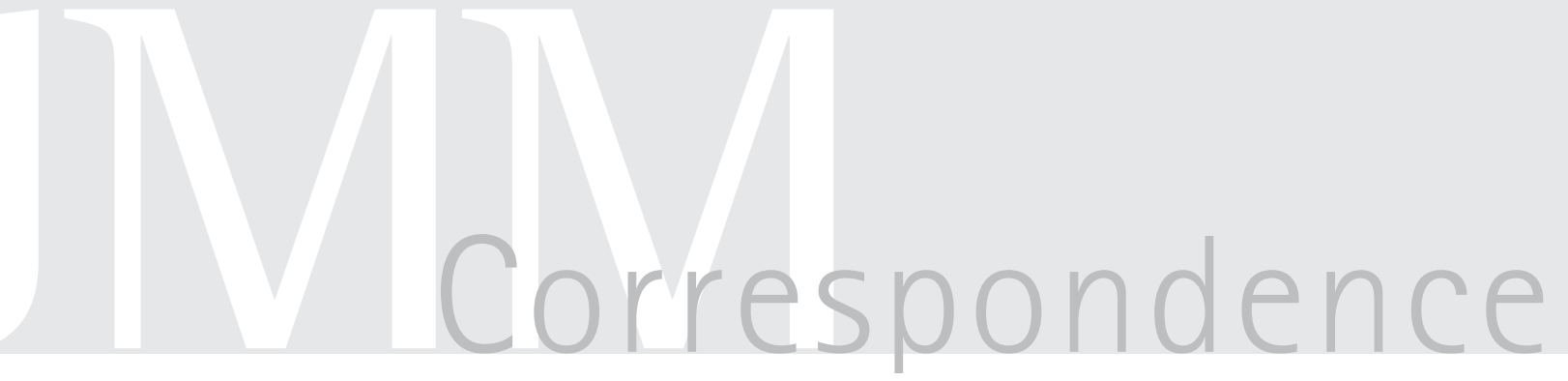

\title{
Plant-based siderophore: a new avenue in molecular medicine for tuberculosis
}

Mycobacterium tuberculosis remains a serious threat to human health, despite significant research on this organism. Study of M. tuberculosis has received increased attention because of an increase in cases of tuberculosis worldwide and a rise in incidence of drug-resistant strains.

Advances in mycobacteriology such as the completion of the M. tuberculosis genome sequence and comparative genomics using microarrays have provided impetus to the gathering of knowledge regarding the pathogenesis of this bacterium (Cole et al., 1998; Wilson et al., 1999). Understanding the molecular pathophysiology of this organism has led to the development of novel therapeutic approaches. However, peptides, proteins and nucleotides or DNA fragments, the new generation of tools against this infection, are facing problems resulting from transport, large molecular dimensions, instability at physiological $\mathrm{pH}$ or sensitivity to temperature. Therefore, revealing the fundamental factors regarding the host-pathogen interaction is a prerequisite for the development of new drug regimens or alternative therapies for this disease.

Mammalian host defence against the pathogen involves restricting access of the organism to iron. In vitro growth studies using standard culture media indicate that siderophore-mediated iron acquisition plays a critical role in growth and metabolism of M. tuberculosis (Olakanmi et al., 2000). Iron confers a distinct advantage on mycobacteria in their survival in the hostile host environment. In response to iron starvation, mycobacteria produce siderophores, iron-storage protein or receptors. Currently, little is known regarding the uptake of iron by the mycobacterial siderophore and the importance of siderophores in mycobacterial pathogenesis. However, exochelins (siderophores) of M. tuberculosis are capable of removing iron from the transferrin lactoferrin and transferring it to the cell wall of mycobacteria (Gobin \& Horwitz, 1996). A ten-gene cluster spanning $24 \mathrm{~kb}$ of the M. tuberculosis genome encoding enzymes for production of a siderophore (mycobactin) has been reported (Quadri et al., 1998).

Recently, a compound has been isolated from a root extract of the leguminous plant Tephrosia purpurea that solubilizes the compound rock iron $\left[\mathrm{Fe}(\mathrm{OH})_{3}\right]$ and helps in plant metabolism (Aggarwal et al., 1999). This compound is also capable of inhibiting growth of $M$. tuberculosis $\mathrm{H}_{37} \mathrm{RA}$ under invitro conditions (Rajiv et al., 2001). The mechanism of action of this compound is through competition with the bacteria for iron in the environment.

We therefore propose a search for plantbased compounds that will generate new avenues to be exploited for human protection against tuberculosis. The future challenges to be met include determining the value of such plant-based compounds against invading bacteria and their effects on different components in the eukaryotic cell. This will resolve the formulation of these compounds and define an appropriate delivery system for the treatment of this infection.

\author{
T. Dam ${ }^{1}$ and C. R. Babu ${ }^{2}$ \\ ${ }^{1}$ Dryden Hall, Room no. 216, Department \\ of Biomedical Sciences, Oregon State \\ University, Corvallis, OR 97331, USA
}

${ }^{2}$ Department of Botany, University of Delhi, Delhi, 110007, India

Correspondence: Tapen Dam

(tapen1@yahoo.com)

Aggarwal, K. K., Rajiv, J. \& Babu, C. R. (1999). A rock-iron-solubilizing compound from root exudates of Tephrosia purpurea. J Chem Ecol 25, 2327-2336.

Cole, S. T., Brosch, R., Parkhill, J. \& 39 other authors (1998). Deciphering the biology of Mycobacterium tuberculosis from the complete genome sequence. Nature 393, 537-544.

Gobin, J. \& Horwitz, M. A. (1996). Exochelins of Mycobacterium tuberculosis remove iron from human iron-binding proteins and donate iron to mycobactins in the M. tuberculosis cell wall. J Exp Med 183, 1527-1532.

Olakanmi, O., Britigan, B. E. \& Schlesinger, L. S. (2000). Gallium disrupts iron metabolism of mycobacteria residing within human macrophages. Infect Immun 68, 5619-5627.

Quadri, L. E., Sello, J., Keating, T. A., Weinreb, P. H. \& Walsh, C. T. (1998). Identification of a Mycobacterium tuberculosis gene cluster encoding the biosynthetic enzymes for assembly of the virulence-conferring siderophore mycobactin. Chem Biol 5, 631-645.

Rajiv, J., Dam, T., Kumar, S., Bose, M., Aggarwal, K. K. \& Babu, C. R. (2001). Inhibition of the in-vitro growth of Mycobacterium tuberculosis by a phytosiderophore. J Med Microbiol 50, 916-918.

Wilson, M., DeRisi, J., Kristensen, H. H., Imboden, P., Rane, S., Brown, P. O. \& Schoolnik, G. K. (1999). Exploring drug-induced alterations in gene expression in Mycobacterium tuberculosis by microarray hybridization. Proc Natl Acad Sci U S A 96, 12833-12838. 